Supporting Information

\title{
Hierarchical Cellular Structured Ceramic Nanofibrous Aerogels with Temperature-Invariant Superelasticity for Thermal Insulation
}

Lvye Dou ${ }^{\dagger}$, Xinxin Zhang ${ }^{\dagger}$, Xiaota Cheng ${ }^{\dagger}$, Zongmin Ma ${ }^{\ddagger}$, Xueqin Wang ${ }^{\ddagger, \S}$, Yang Si ${ }^{*,+, \neq, \S,}$ Jianyong $\mathrm{Yu}^{\S}$ and Bin Ding*,+,,,§

${ }^{\dagger}$ State Key Laboratory for Modification of Chemical Fibers and Polymer Materials, College of Textiles, Donghua University, Shanghai 201620, P. R. China

‡College of Materials Science and Engineering, Donghua University, Shanghai 201620, P. R. China

$\S$ Innovation Center for Textile Science and Technology, Donghua University, Shanghai 200051, P. R. China

*E-mail: yangsi@dhu.edu.cn.

* E-mail: binding@dhu.edu.cn

This file includes:

Figure S1.-S12. and Table S1.-S2.

Movie S1.-S5. 
1. Figure S1.-S12. and Table S1.-S2

(a)

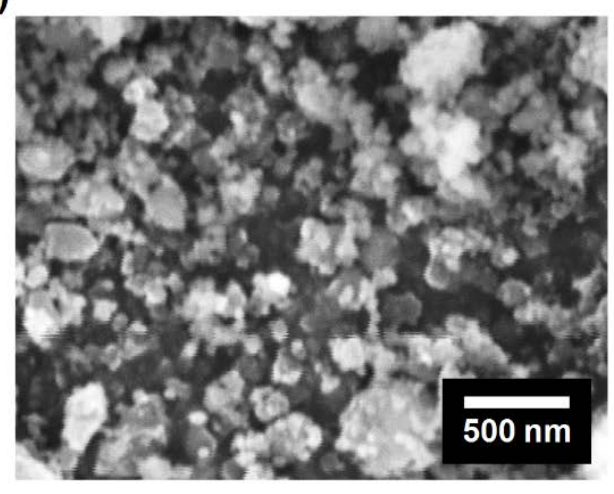

(b)

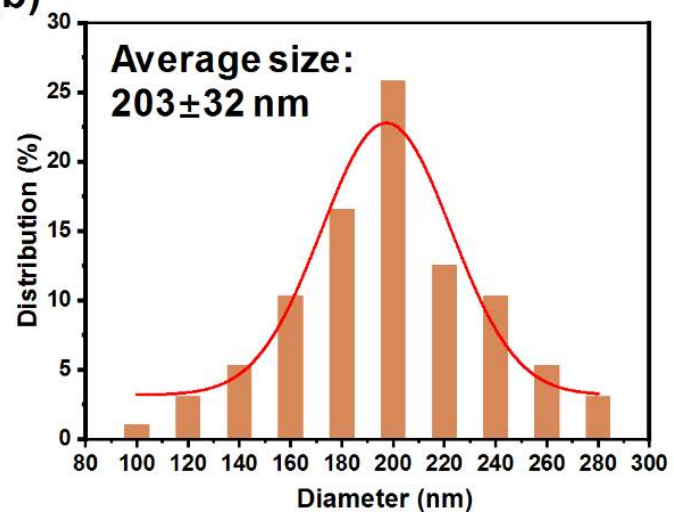

Figure S1. (a) SEM image of SNAs. (b) Histogram demonstrating the size distribution of SNAs. 
(a)

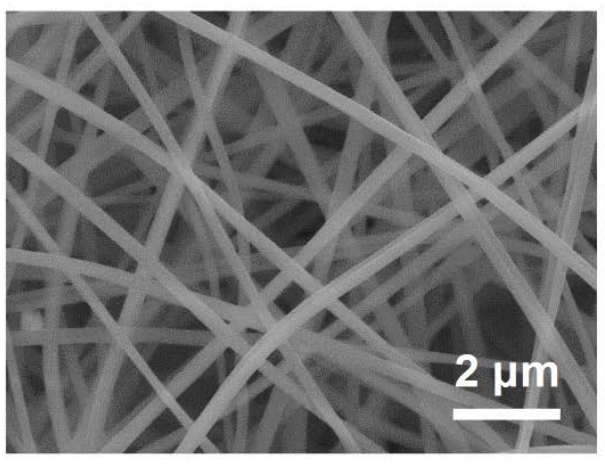

(b)

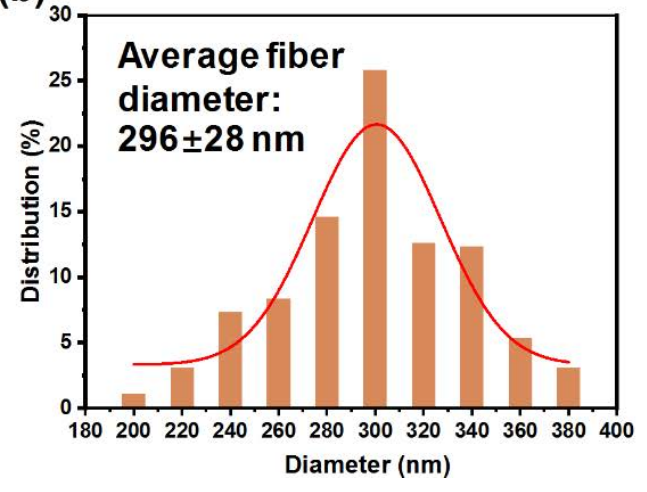

Figure S2. (a) SEM image of electrospun SNFs. (b) Histogram demonstrating the fiber diameter distribution of SNFs. 


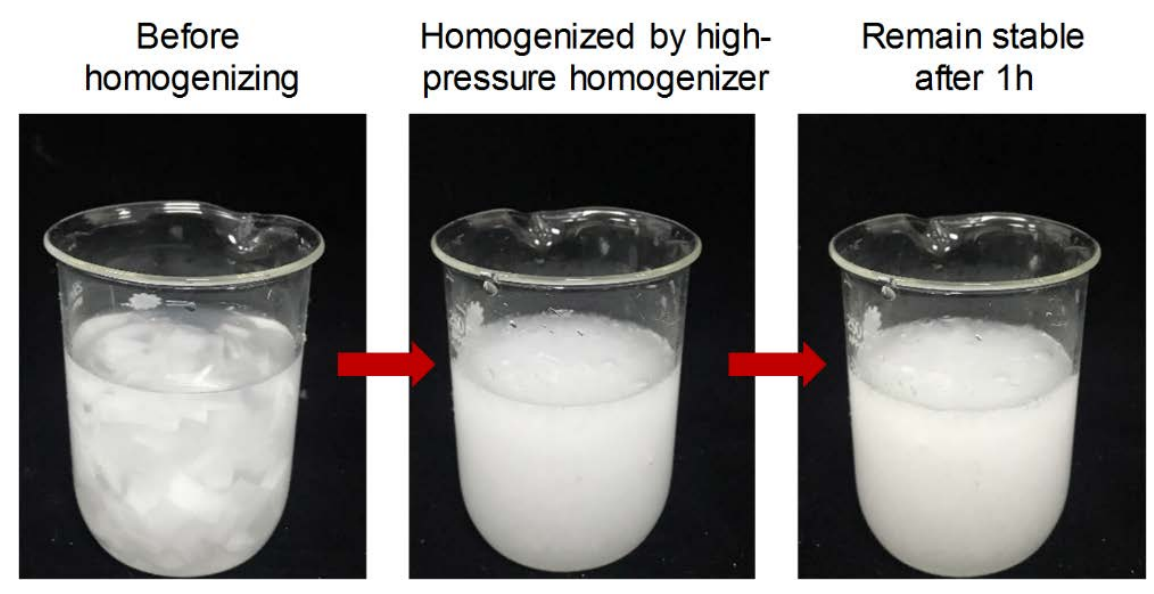

Figure S3. Optical photographs showing the preparation of $\mathrm{SNFs} / \mathrm{SNAs} / \mathrm{SiO}_{2}$ sol/PEO dispersions by a high-pressure homogenizer. 


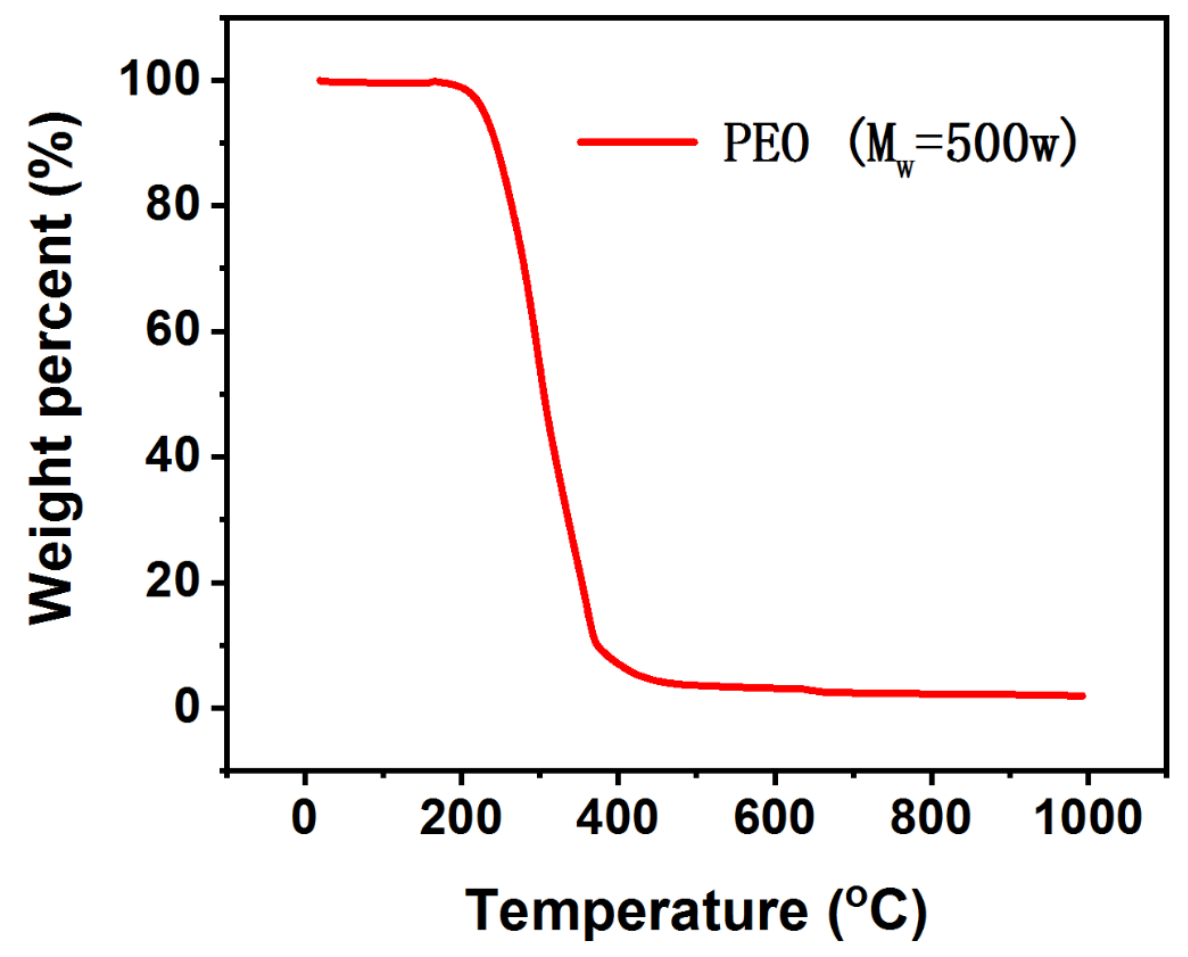

Figure S4. The TGA curve of PEO. 
(a)

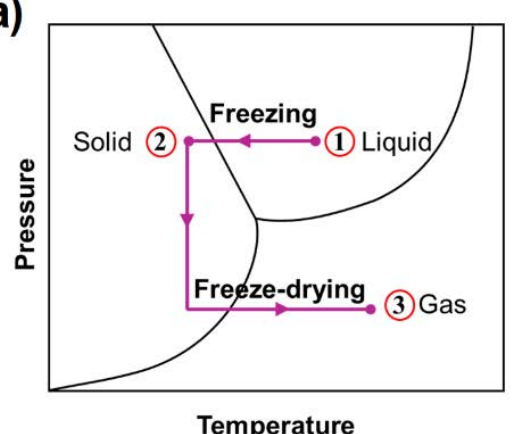

(c)

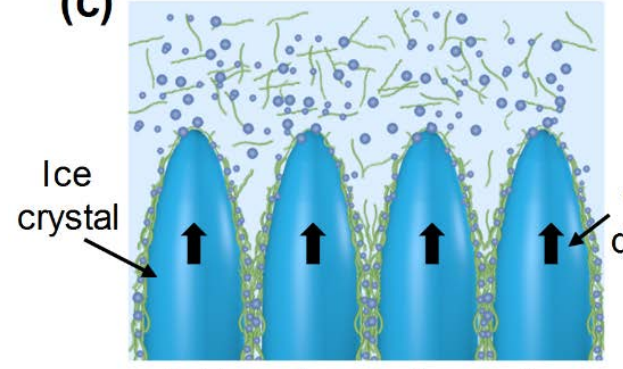

2. Freezing of disperation (b)

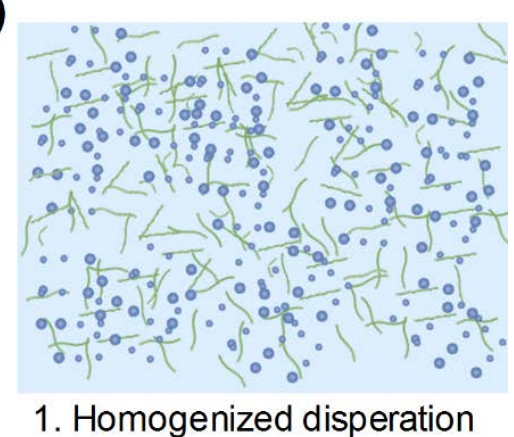

(d)

Growth

direction

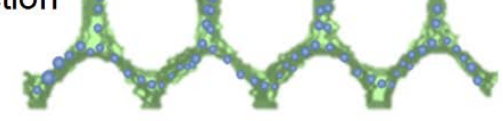

3. Sublimation of ice crystal

Figure S5. (a) Phase diagram of the three processing steps of freeze-shaping. (b-d) Schematical illustration of the formation principles for the cellular structure by phase separation. 


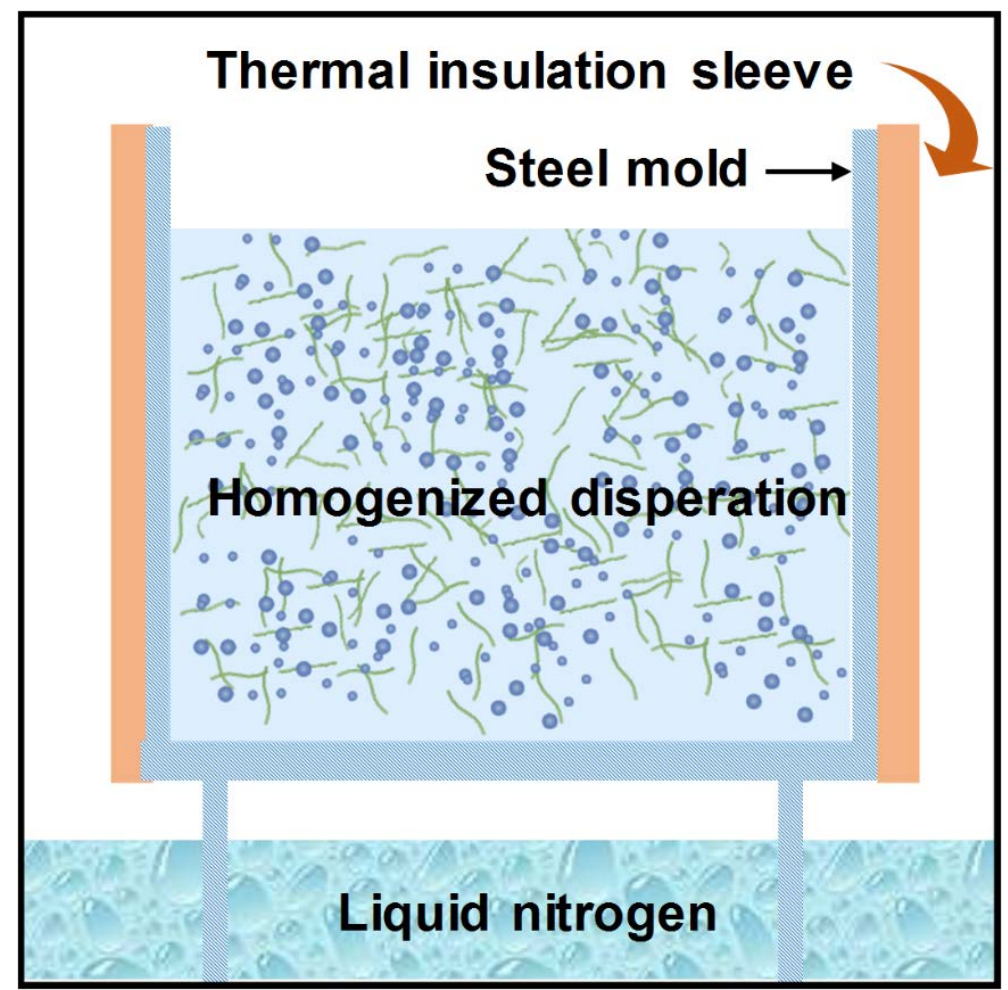

Figure S6. Schematic illustration of the homemade directional freezing mold. 


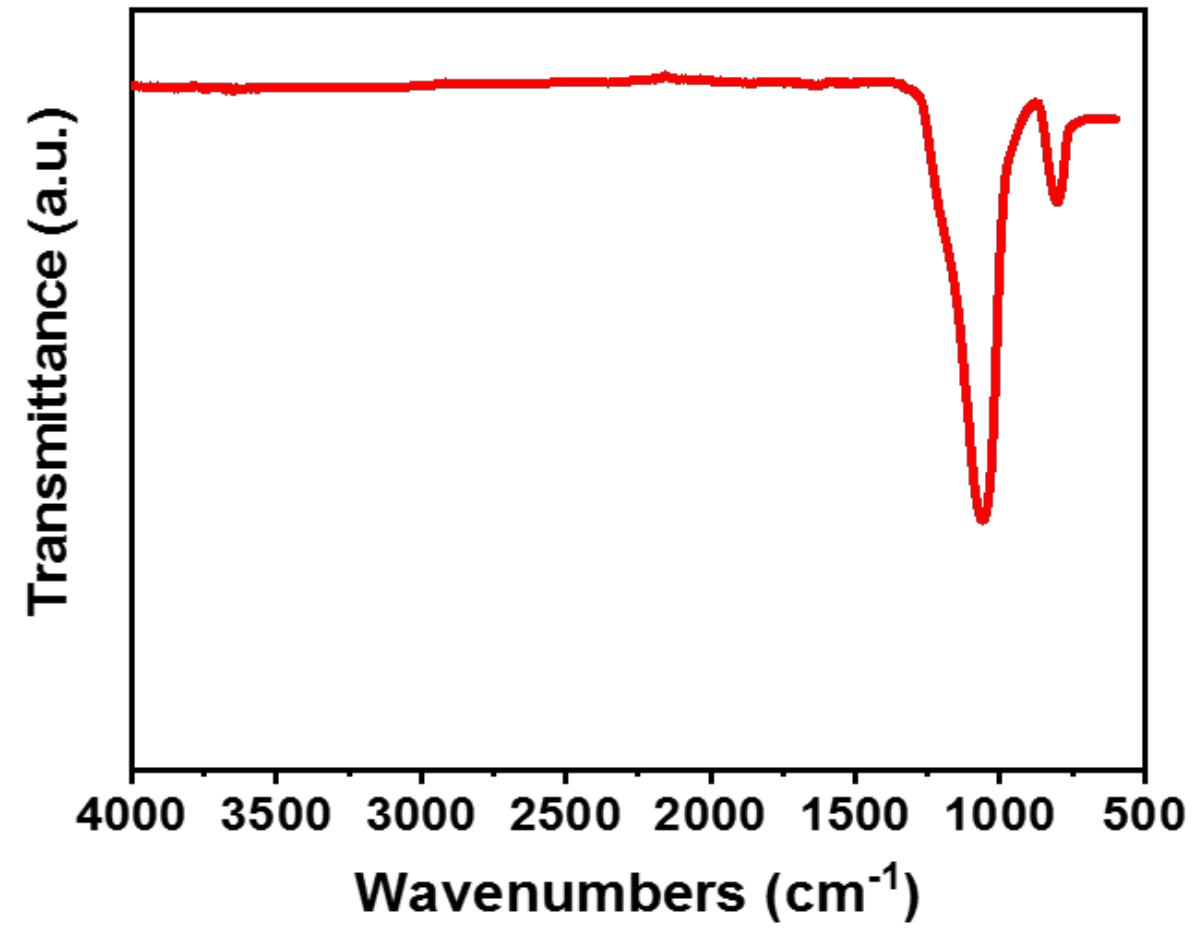

Figure S7. The FT-IR spectrum of the prepared HNAs. 


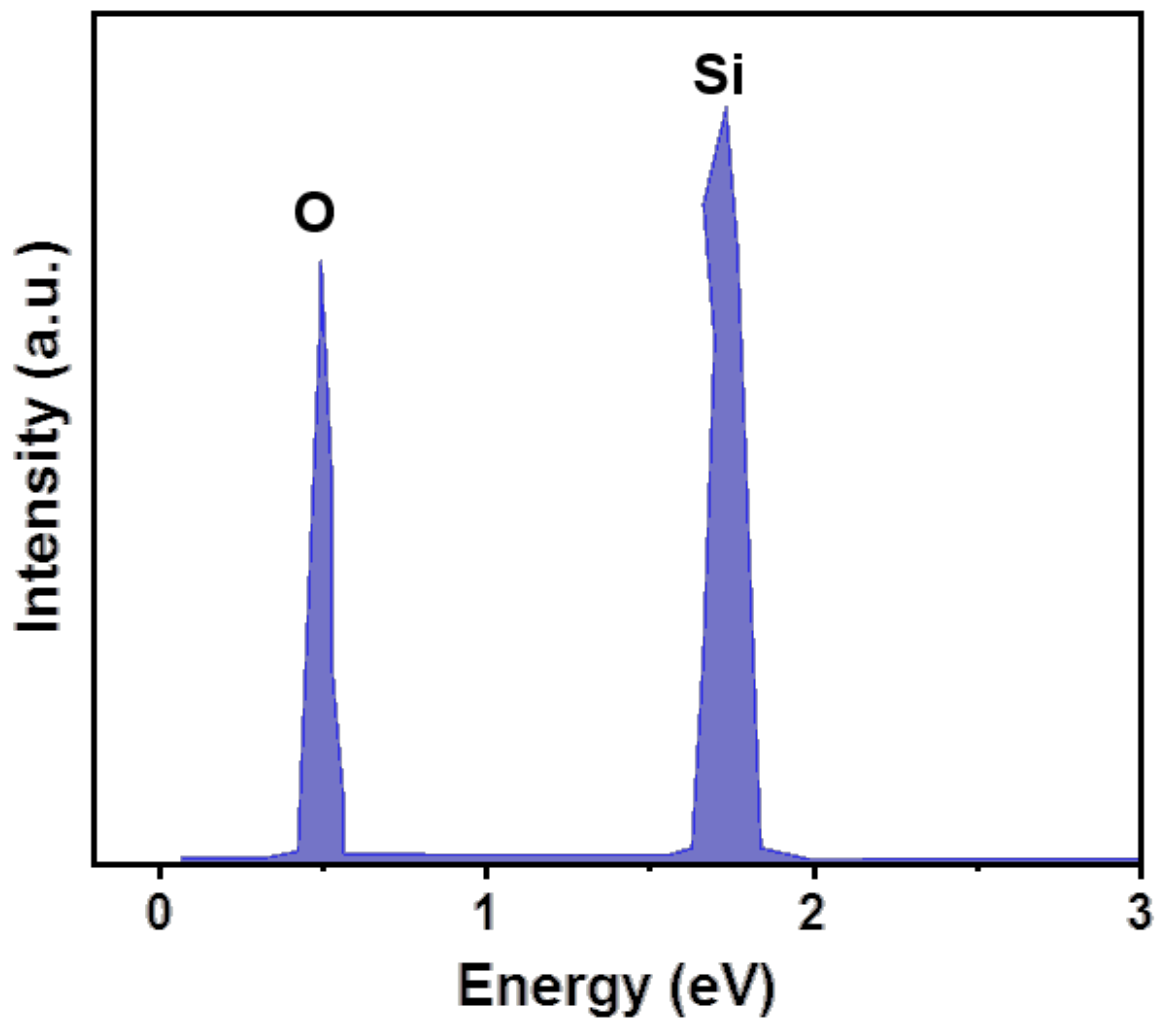

Figure S8. The EDXS analysis of the prepared HNAs. 


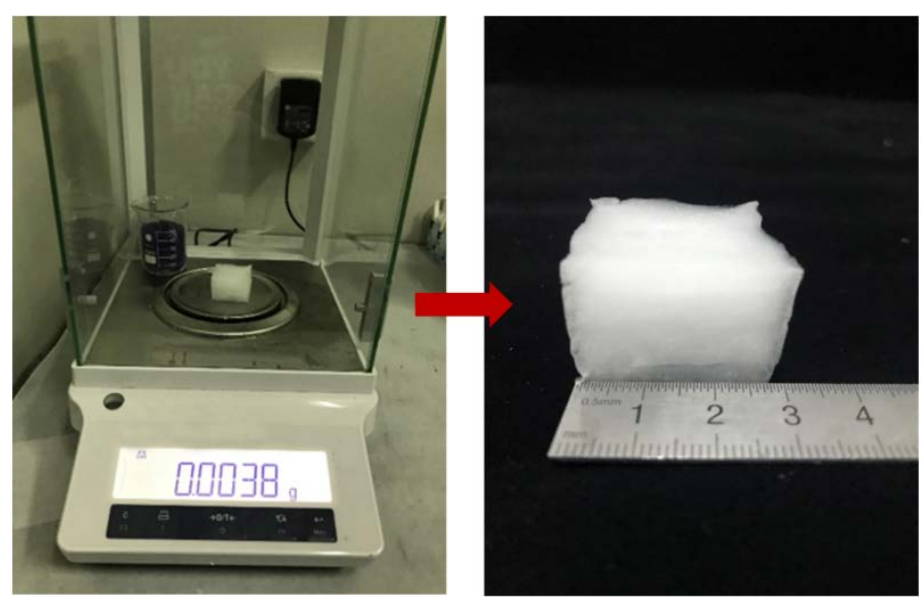

Figure S9. The weight measurement process for an ultralight HNA $\left(19.1 \mathrm{~cm}^{-3}\right)$ with a mass of $3.8 \mathrm{mg}$, which is corresponding to a density of $0.2 \mathrm{mg} \mathrm{cm}^{-3}$ (the content of SNAs in this aerogel is $30 \mathrm{wt} \%$ to SNFs). 


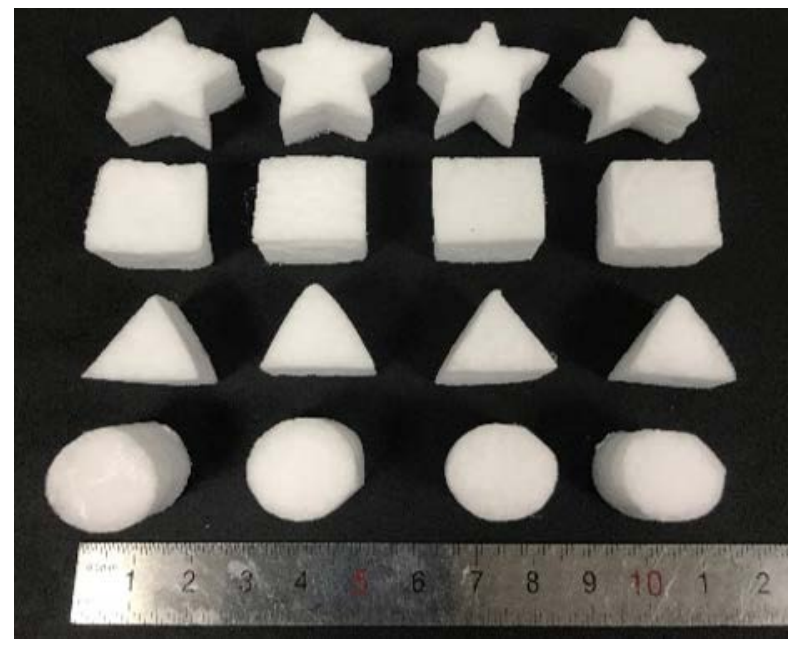

Figure S10. An optical photograph of HNAs with diverse shapes. 
(a)

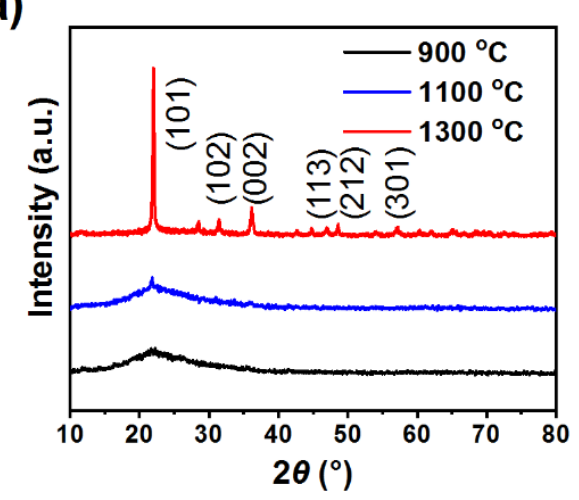

(c)

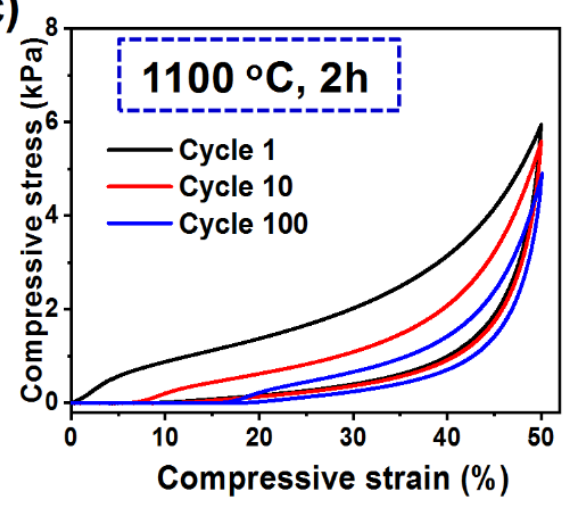

(b)

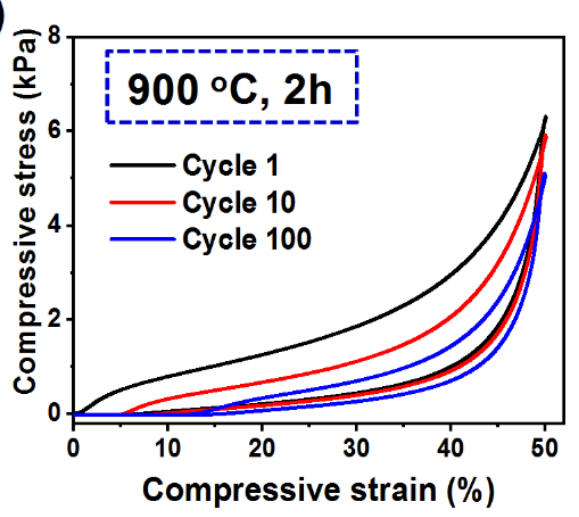

(d)

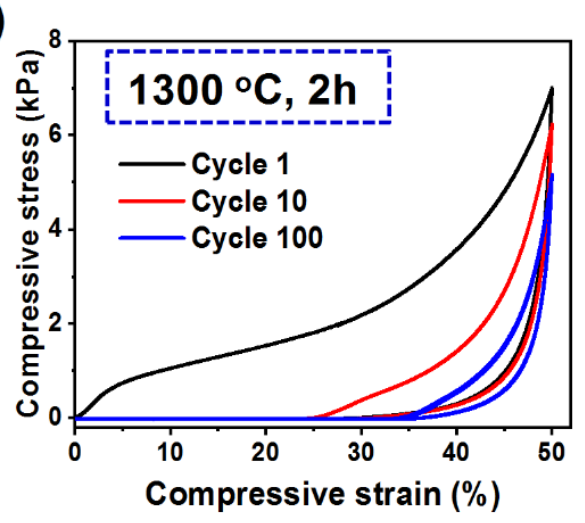

Figure S11. XRD patterns (a) and 100-cycle compressive test (b-d) of HNAs after calcined at 900, 1100 , and $1300^{\circ} \mathrm{C}$ for $2 \mathrm{~h}$. 
(a)

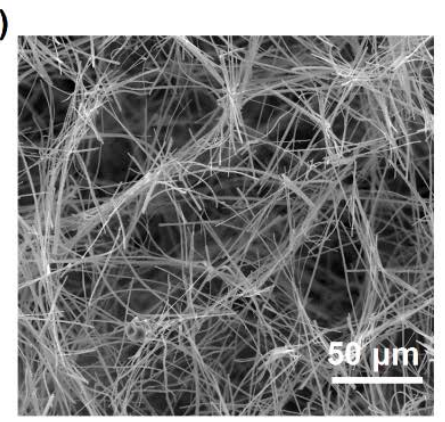

(d)

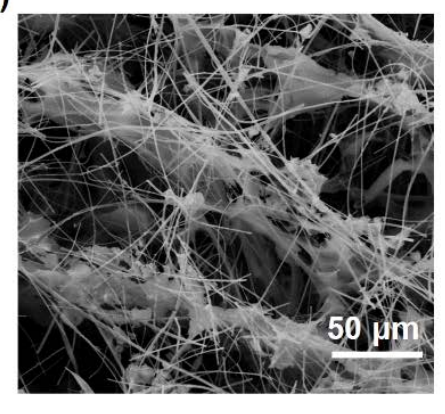

(b)

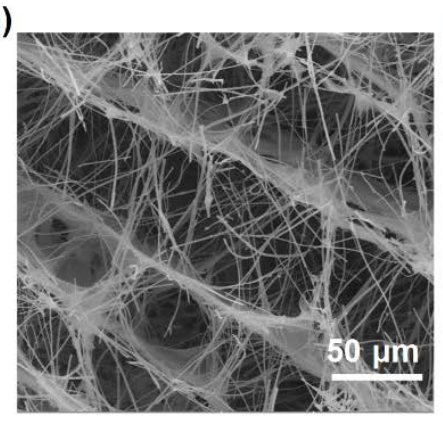

(e)

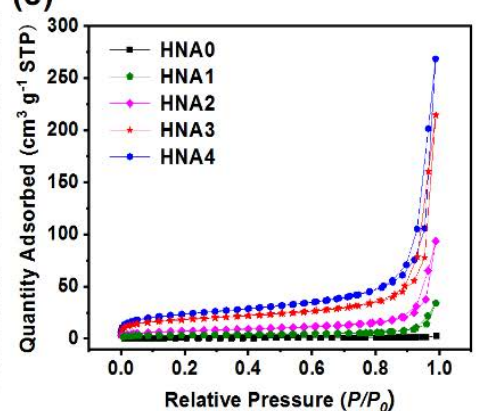

(c)

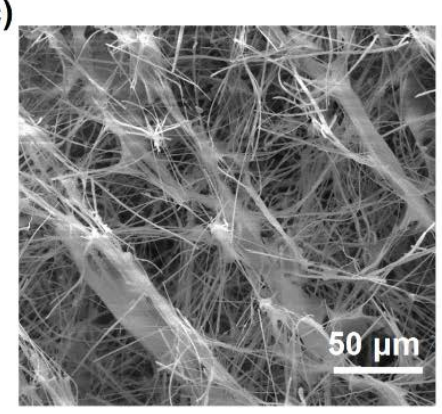

(f)

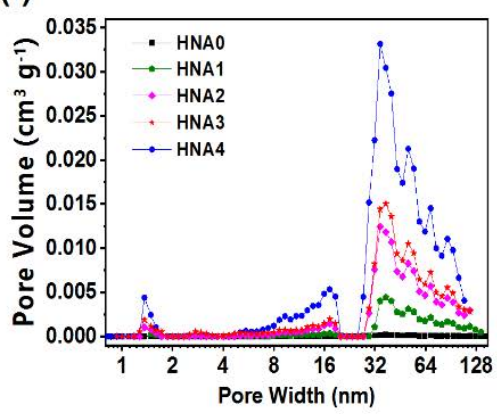

Figure S12. SEM images of HNAs with different content of SNAs (a) 10\%, (b) 20\%, (c)

30\%, (d) 40\%. $\mathrm{N}_{2}$ adsorption-desorption isotherms (e) and pore size distribution (f) curves of HNAs. 
Table S1 The relevant density and porosity of HNAs with different SNAs.

\begin{tabular}{cccc}
\hline Samples & $\begin{array}{c}\text { Content of SNAs } \\
\mathbf{( \% )}\end{array}$ & $\begin{array}{c}\text { Density } \\
\left(\mathbf{m g ~ c m}^{-3}\right)\end{array}$ & $\begin{array}{c}\text { Porosity } \\
\mathbf{( \% )}\end{array}$ \\
\hline HNA0 & 0 & 5 & 99.77 \\
HNA1 & 10 & 5.5 & 99.75 \\
HNA2 & 20 & 6 & 99.73 \\
HNA3 & 30 & 6.5 & 99.70 \\
HNA4 & 40 & 7 & 99.68 \\
\hline
\end{tabular}


Table S2: The relevant properties of HNAs and other commonly used thermal insulation materials.

\begin{tabular}{c|c|c|c|c}
\hline Materials & $\begin{array}{c}\text { Density } \\
\left(\mathrm{mg} \mathrm{cm}^{-3}\right)\end{array}$ & $\begin{array}{c}\text { Thermal } \\
\text { conductivity } \\
\left(\mathrm{W} \mathrm{m}^{-1} \mathrm{~K}^{-1}\right)\end{array}$ & $\begin{array}{c}\text { Maximum } \\
\text { working } \\
\text { temperature } \\
\left({ }^{\circ} \mathrm{C}\right)\end{array}$ & Compressibility \\
\hline HNAs & $\mathbf{0 . 2 ~ 3 0}$ & $\mathbf{0 . 0 2 3 - \mathbf { 0 . 0 2 6 }}$ & $\mathbf{1 1 0 0}$ & Elastic \\
$\mathrm{SiO}_{2}$ nanoparticle aerogels & $0.16-100$ & $0.018-0.025$ & 1000 & Brittle \\
PU foams & $30-200$ & $0.027-0.2$ & 200 & Elastic \\
Cellulose aerogels & $40-200$ & $0.04-0.06$ & 350 & Elastic \\
Carbon aerogels & $5-200$ & $0.03-0.1$ & 600 & Elastic \\
Glass fiber/SiO 2 aerogels & $50-300$ & $0.04-0.2$ & 800 & Elastic \\
Nonwovens & $50-200$ & $0.05-0.3$ & 150 & Elastic \\
\hline
\end{tabular}


2. Movie S1 - S5

Movie S1 Compression and recovery processes of HNAs, indicating the negative Poisson's ratio property and superelasticity.

Movie S2 Compression testing in liquid nitrogen.

Movie S3 Compression testing in the flame of a butane blowtorch.

Movie S4 Fresh flower protected by HNAs, indicating the high-temperature thermal insulation performance.

Movie S5 Fire resistance performance of HNAs. 